\title{
Using Microwave Irradiation for synthesis of Imides consist of Pyromellitimide \\ Habib Saedi
}

Polymer Research Unit, College of Science. Al Mustansiriya University, Baghdad, Iraq

$$
\text { E-mail: Habibmahtook@yahoo.com }
$$

\section{Abstract}

Bispyromellitimides are an important class of substrates in polymer chemistry as monomers in polyimides or their copolymers synthesis. A fast and efficient microwave-assisted synthetic procedure for the preparation of series of these compounds $3(\mathrm{a}-\mathrm{h})$ from the reaction of pyromellitic anhydride and aniline or its derivatives $(\mathrm{a}-\mathrm{h})$ is described. Elemental analysis, FT-IR and H-FT-NMR Spectra revealed the confirmation of these compounds in good agreement.

Keywords: Bispyromellitimide; Pyromellitic anhydride; substituted aniline; microwave

\section{Council for Innovative Research}

Peer Review Research Publishing System

Journal: Journal of Advances in Chemistry

Vol. 10, No. 2

editorjaconline@gmail.com

www.cirjac.com 


\section{Introduction}

Microwave-assisted organic synthesis has been known since 1986[1]. The promotion of microwave assisted reactions inorganic chemistry has improved the speed, reduced cost, reduced energy spent making it a sustainable process and is widely heralded as "green chemistry" measures [2, 3] whose applications are promoted today to minimize the use of nonrenewable resources as well as polluting solvent, to reduce generation of secondary products which are often toxic and to reduce the emission of harmful gases [4]. Therefore, a variety of reactions such ashydrolysis[5], deacetylation[6],aromatic nucleophilic substitutions[7], esterification[8],cycloaddition[9] and polymer synthesis[10-13] had been facilitated by microwave irradiation.

The reaction of aniline or its derivatives with dianhydride such as pyromellitic dianhydride (PYMD) is well-known, because theproduct amic acid ,imideor bisimide are an important class of substratesin polymer chemistry as monomers in polyimides or their copolymers synthesis.Bisimideshave a strategic material for synthesis poly(ester-imide)[14-15], Poly(amide-imide)[16-17]or other polyimide copolymers[18]to improve processability, structural modifications may be needed to decrease the melting temperatures or to increase the solubility of polyimides in a solution.Bisimides generally be synthesized by two routs;two-step method via chemical imidizationin which an amine reacts with the anhydride, followed bydehydration of the intermediate amic acid, usually promoted by acid[19] or one pot synthesis by the condensationreaction of an dianhydride with an aminein a mixture of acetic acid solution and pyridine.These two methodsarelimited to the use of amines as starting material excluding those, that are unstable under the dehydration conditions or need a long time. Few attempts were carried out to synthesis imides using microwave irradiation. These attempts deal with synthesis of imide-acid derivatives[20] and maleimide[21] using a monoanhydride and a-amino acids. This paper report is an efficient method for the synthesis some bispyromellitimides3 (a-h) from the reaction of pyromellitic dianhydride as dianhydride and aniline or its derivatives in presence of small amount of acetic acid and few drops of pyridine using microwave irradiation.

\section{Experimental}

\section{Materials}

4-Aminobenzoic acid (a), aniline(b) , 4-chloroaniline (c), 3-chloroaniline (d), 4-bromooaniline, 4-aminiphenol (f), 4nitroaniline (g),4-sulfanilinic acid (h), pyromellitic dianhydride (PMD), glacial acetic acid, pyridine (py), were purchased as analytical grade products and used as received.

\section{Instrumental and Measurements}

${ }^{1} \mathrm{H}-\mathrm{NMR}$ spectra were obtained on a $500 \mathrm{MHz}$ FT-NMR spectrometer (Bruker Instruments, model Avance-w 500, Germany) at room temperature using DMSO- $\mathrm{d}_{6}$ as a solvent and TMS as an internal standard. FT-IR spectra were obtained with a JASCO model FT/IR 4200 in the $4000-400 \mathrm{~cm}^{-1}$ range on KBr pellets. Elemental analysis were performed with a Perkin-Elmer $2400 \mathrm{CHN}$ analyzer. Melting points were determined by stuart SMP 30 and uncorrected. All reactions were performed on a domestic microwave oven which was modified by our laboratory to include a reflux condenser and stirring unit.

\section{Synthesis of Bispyromellitimides}

A series of bispyromellitimides(3a-3h) were synthesized from the reaction of pyromellitic anhydride with aniline or its derivatives (a-h) (described below and shown in Scheme 1).

\section{Synthesis of N,N'-bis(4-carboxyphenyl)pyromellitimide acid}

To a $100 \mathrm{~mL}$ round bottomed flask containing a mixtures of $3.0 \mathrm{~g}(13.7 \mathrm{mmol})$ of PMD and $3.757 \mathrm{~g}(27.4 \mathrm{mmol})$ of 4 aminobenzoic acid, $20 \mathrm{~mL}$ of glacial acetic acid and few drops of pyridine were added. The flask then provided with a condenser and a magnetic stirrer, flashed with nitrogen and microwave irradiated at room temperature (power input: 400 W) for 10 minutes. After this period time of reaction the reaction mixture was filtered. The solid obtained was washed thoroughly with water and methanol to eliminate the remaining pyridine and acetic acid, refluxed with acetone and dried under vacuum at $60-70{ }^{\circ} \mathrm{C}$ overnight. The yield is $97 \% . \mathrm{Mp}>300 \mathrm{C}^{\circ}$. The elemental analysis of pale yellow solid product calculated for $\left(\mathrm{C}_{24} \mathrm{H}_{12} \mathrm{O}_{8} \mathrm{~N}_{2}\right) \mathrm{C}, 63.16 ; \mathrm{H}, 2.65 ; \mathrm{N}, 6.14 ;$ Found $\mathrm{C}, 63.13 ; \mathrm{H}, 2.70 ; \mathrm{N}, 6.17$. IR $(\mathrm{KBr}) \tilde{V}$ 3500-2500, 1786, $1725,1607,1515,1390,725 \mathrm{~cm}^{-1}$, ${ }^{1} \mathrm{H}-\mathrm{NMR}$ (DMSO-d6) $\delta: 7.67-8.43(10 \mathrm{H}$, aromatic), $13.18(2 \mathrm{H}, \mathrm{OH}) \mathrm{ppm}$.

The other bispyromellitimides were prepared on the same procedure.Time of reaction, melting point and elemental analysis of therearelisted in Table 1. Pure and dry samples of the other prepared bispyromellitimides were characterized by FT-IR Table 2. 
Table 1:Time of reaction, Melting Point, Yield\% and Elemental Analysis of Prepared Bispyromellitimides

\begin{tabular}{|c|c|c|c|c|c|c|c|c|c|c|c|}
\hline \multirow{3}{*}{$\begin{array}{l}\text { Code } \\
\text { No. }\end{array}$} & \multirow{3}{*}{$\begin{array}{l}\text { Compound } \\
\text { Name }\end{array}$} & \multirow{3}{*}{$\begin{array}{l}\text { Time } \\
\text { (min) }\end{array}$} & \multirow{3}{*}{$\begin{array}{l}\mathrm{m} \cdot \mathrm{p} \\
\left(\mathrm{C}^{\circ}\right)\end{array}$} & \multirow{3}{*}{$\begin{array}{c}\text { Yield } \\
\%\end{array}$} & \multirow{3}{*}{$\begin{array}{l}\text { Formula } \\
\text { M. Wt. } \\
(\mathrm{g} / \mathrm{mol})\end{array}$} & \multicolumn{6}{|c|}{ Elemental Analysis } \\
\hline & & & & & & \multicolumn{2}{|c|}{ C \% } & \multicolumn{2}{|c|}{$\mathrm{H} \%$} & \multicolumn{2}{|c|}{$\mathrm{N} \%$} \\
\hline & & & & & & Cal. & Fou. & Cal. & Fou & Cal. & Fou. \\
\hline $3 a$ & $\begin{array}{l}\mathrm{N}, \mathrm{N}^{\prime}-\mathrm{Bis}(4- \\
\text { carboxyphenyl) } \\
\text { pyromellitimide }\end{array}$ & 8 & $>300$ & 97 & $\begin{array}{l}\mathrm{C}_{24} \mathrm{H}_{12} \mathrm{O}_{8} \mathrm{~N}_{2} \\
(456.35)\end{array}$ & 63.16 & 63.13 & 2.65 & 2.70 & 6.14 & 6.17 \\
\hline $3 b$ & $\begin{array}{l}\text { N,N'-Diphenyl } \\
\text { pyromellitimide }\end{array}$ & 10 & $>300$ & 93 & $\begin{array}{l}\mathrm{C}_{22} \mathrm{H}_{12} \mathrm{O}_{4} \mathrm{~N}_{2} \\
(368.33)\end{array}$ & 71.73 & 71.69 & 3.24 & 3.26 & 7.60 & 7.58 \\
\hline $3 c$ & $\begin{array}{l}\text { N,N'-Bis(4- } \\
\text { chlorophenyl) } \\
\text { pyromellitimide }\end{array}$ & 12 & $>300$ & 91 & $\begin{array}{l}\mathrm{C}_{22} \mathrm{H}_{10} \mathrm{O}_{4} \mathrm{~N}_{2} \mathrm{Cl}_{2} \\
(437.22)\end{array}$ & 60.43 & 60.41 & 2.30 & 2.37 & 6.41 & 6.38 \\
\hline $3 d$ & $\begin{array}{l}\text { N,N'-Bis(3- } \\
\text { chlorophenyl) } \\
\text { pyromellitimide }\end{array}$ & 12 & $>300$ & 90 & $\begin{array}{l}\mathrm{C}_{22} \mathrm{H}_{10} \mathrm{O}_{4} \mathrm{~N}_{2} \mathrm{Cl}_{2} \\
\text { (437.22) }\end{array}$ & 60.43 & 60.39 & 2.30 & 2.28 & 6.41 & 6.39 \\
\hline $3 e$ & $\begin{array}{l}\mathrm{N}, \mathrm{N} \text { '-Bis(4- } \\
\text { bromophenyl) } \\
\text { pyromellitimide }\end{array}$ & 12 & $>300$ & 93 & $\begin{array}{l}\mathrm{C}_{22} \mathrm{H}_{10} \mathrm{O}_{4} \mathrm{~N}_{2} \mathrm{Br}_{2} \\
(526.12)\end{array}$ & 50.22 & 50.27 & 1.91 & 1.93 & 5.33 & 5.35 \\
\hline $3 f$ & $\begin{array}{l}\text { N,N'-Bis(4- } \\
\text { hydroxyphenyl) } \\
\text { pyromellitimide }\end{array}$ & 12 & $>300$ & 94 & $\begin{array}{l}\mathrm{C}_{22} \mathrm{H}_{12} \mathrm{O}_{6} \mathrm{~N}_{2} \\
(400.33)\end{array}$ & 66.00 & 66.17 & 3.02 & 2.98 & 7.00 & 7.06 \\
\hline $3 g$ & $\begin{array}{l}\mathrm{N}, \mathrm{N} \text { '-Bis(4- } \\
\text { nitrophenyl) } \\
\text { pyromellitimide }\end{array}$ & 15 & $>300$ & 89 & $\begin{array}{l}\mathrm{C}_{22} \mathrm{H}_{10} \mathrm{O}_{8} \mathrm{~N}_{4} \\
(458.34)\end{array}$ & 57.67 & 57.71 & 2.20 & 1.99 & $\begin{array}{l}12.2 \\
2\end{array}$ & 12.26 \\
\hline
\end{tabular}


Table 2: The FT-IR Spectrum of the Prepared Bispyromellitimides (3b-3h)

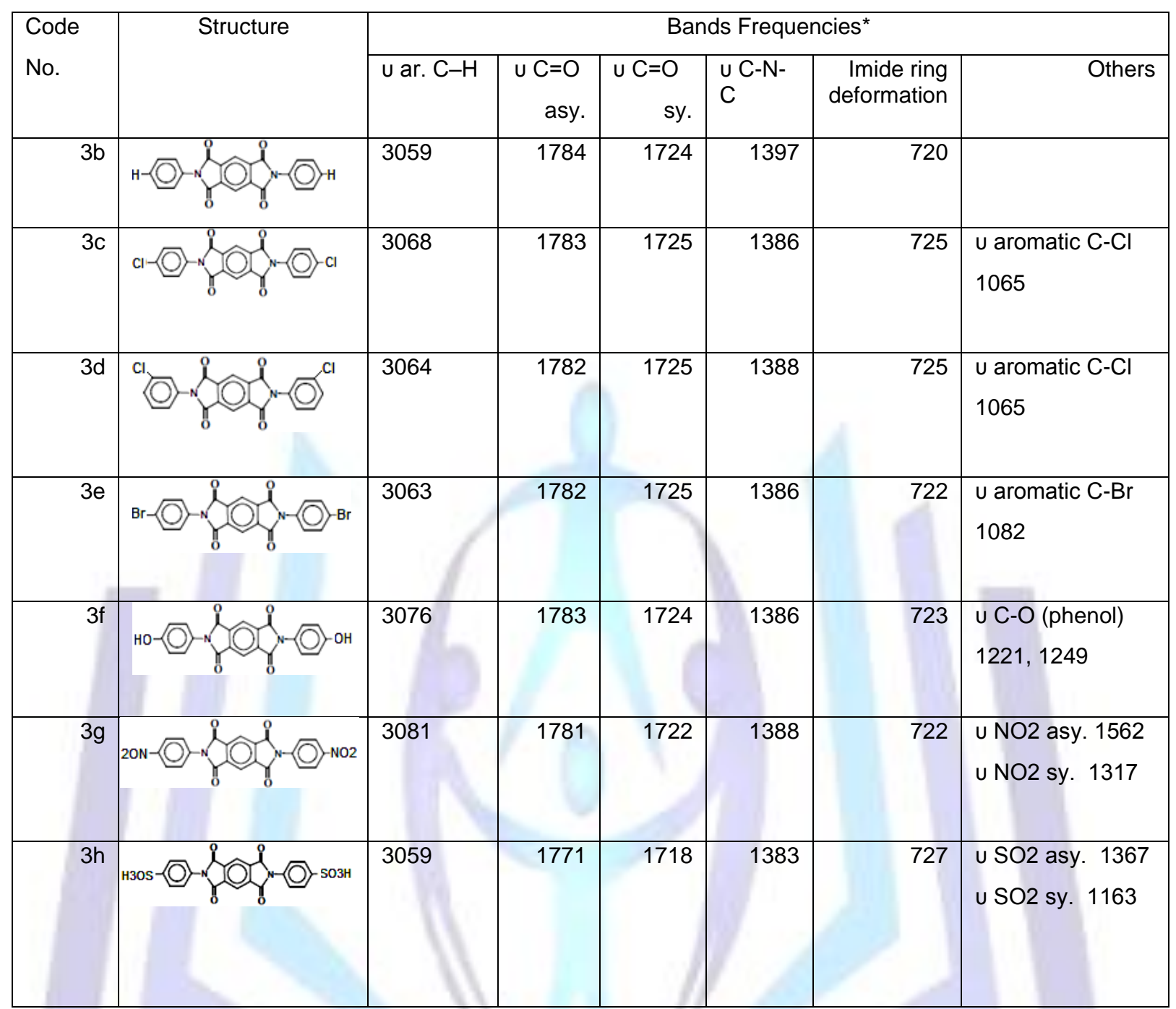

$\left(^{\star}\right): \cup=$ stretching band, $\sigma=$ binding band, sy. = symmetric vibration mode

\section{Results and Discussion}

Bisimides are one of the more important materials in polyimide copolymer synthesis. Among these bisimides, the compound N, N'-bis(4-carboxyphenyl)pyromillitimide(3-a) or its acid chloride be more attractive for synthesis of poly(esterimide), Poly(amide-imide) and other polyimide copolymers[22-23]. This compound has been synthesized under conventional heating via its bisamic acid using a large amount of acetic acid/pyridine (3:2) mixture during 10-12 hours of reaction time[24].In this work the compound N,N'-bis(4-carboxyphenyl)pyromellitimide (3-a) was synthesized from condensation reaction of aquimolar of pyromellitic dianhydride (PMD) with two aquimolar of $p$-amino benzoic acid ( $p$-ABA) in glacial acetic acid and few drops of pyridine using microwave irradiation (Scheme 1). 

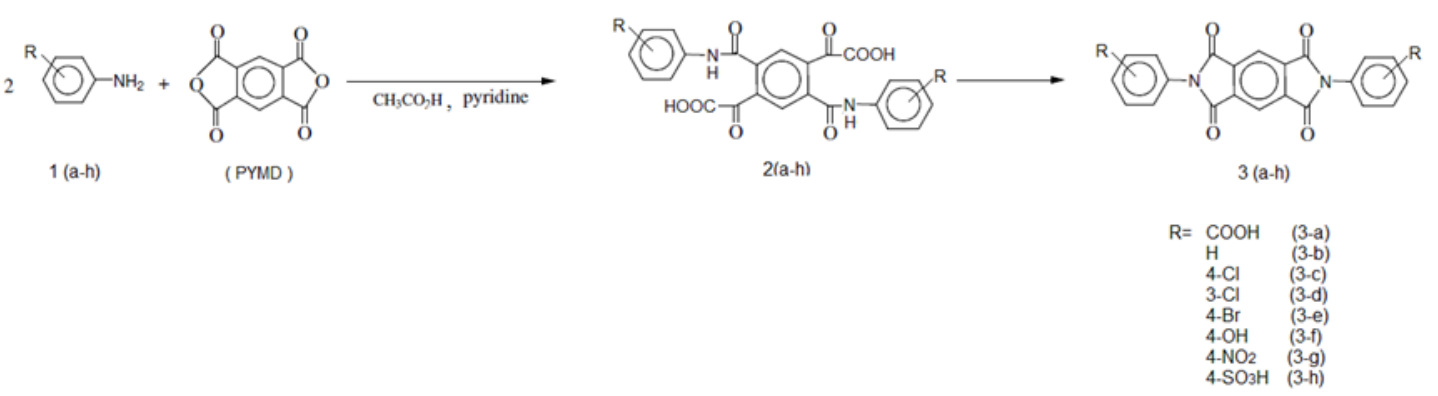

Scheme 1: Synthesis of Bispyromellitimides

The chemical structure of (3a)was identified by FT-IR and ${ }^{1} \mathrm{H}$ FT-NMR spectroscopy. The IR spectrum of (3a) Fig. 1 showed a broad peak from $(3500-2500) \mathrm{cm}^{-1}$, due to the carboxylic moieties. Also the strong absorption due to the presence of cyclic imide linkages is exhibited at $1786.7 \mathrm{~cm}^{-1}(\mathrm{C}=\mathrm{O}$ asymmetrical stretching $), 1725 \mathrm{~cm}^{-1}(\mathrm{C}=\mathrm{O}$ symmetrical stretching), $1390 \mathrm{~cm}^{-1}$ (C-N stretching), 1607, $1515 \mathrm{~cm}^{-1} \quad(-\mathrm{Ph}), 725 \mathrm{~cm}^{-1}$ (imide ring deformation $\mathrm{C}=\mathrm{O}$ bending). The structures of the other prepared compounds have been confirmed by FT-IR, Table 2.

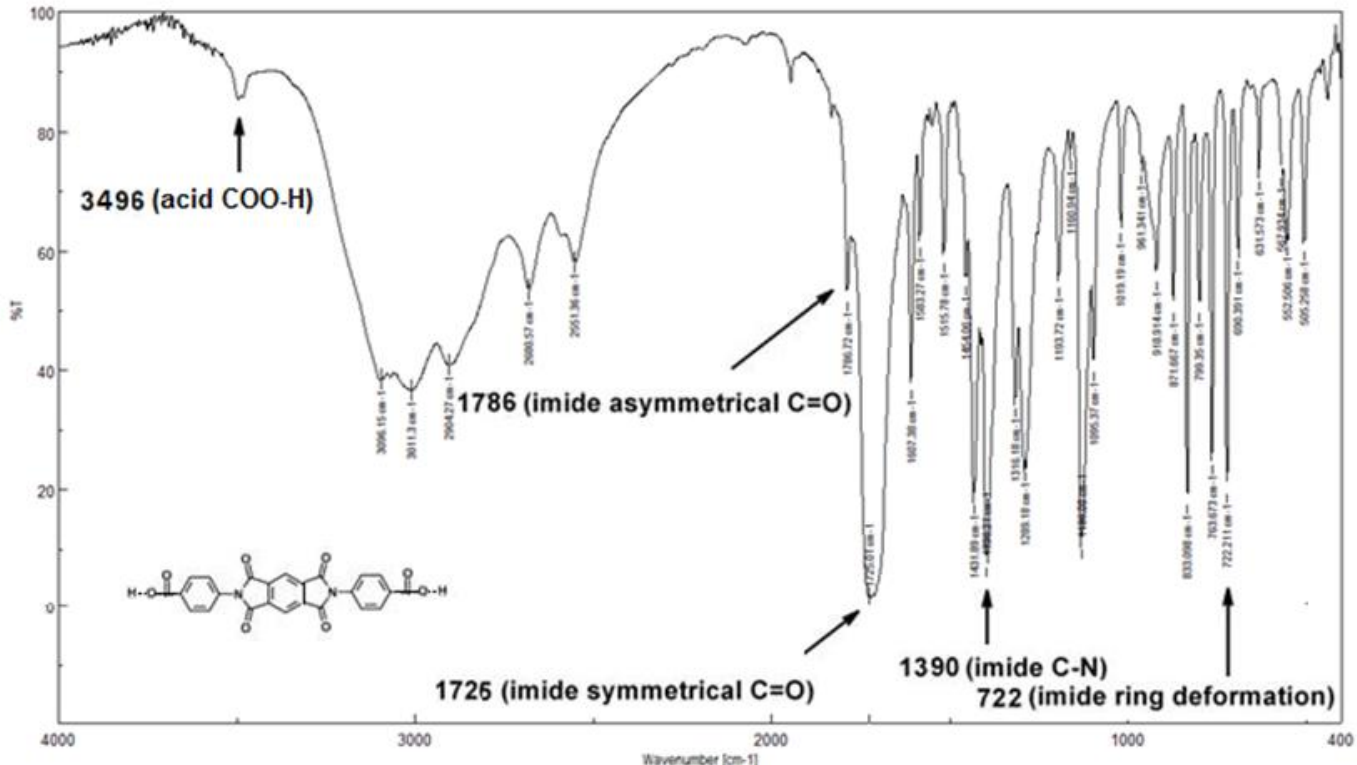

FT-IR Spectra of N-N'-Bis(4-carboxyphenyl)pyromellitimide Figure 1:

In the ${ }^{1} \mathrm{H}$ NMR spectrum the compound (3a) given in Fig. 2, thespecific signals for this product are those for the ten aromatic protons in the range of 7.67 to $8.43 \mathrm{ppm}$ and at $13.18 \mathrm{ppm}$ for the two carboxylic protons. Elemental analysis found $63.13 \%$ for carbon, $2.70 \%$ for hydrogen and $6.17 \%$ for nitrogen in which that to be in good agreement with the theoretical values. 


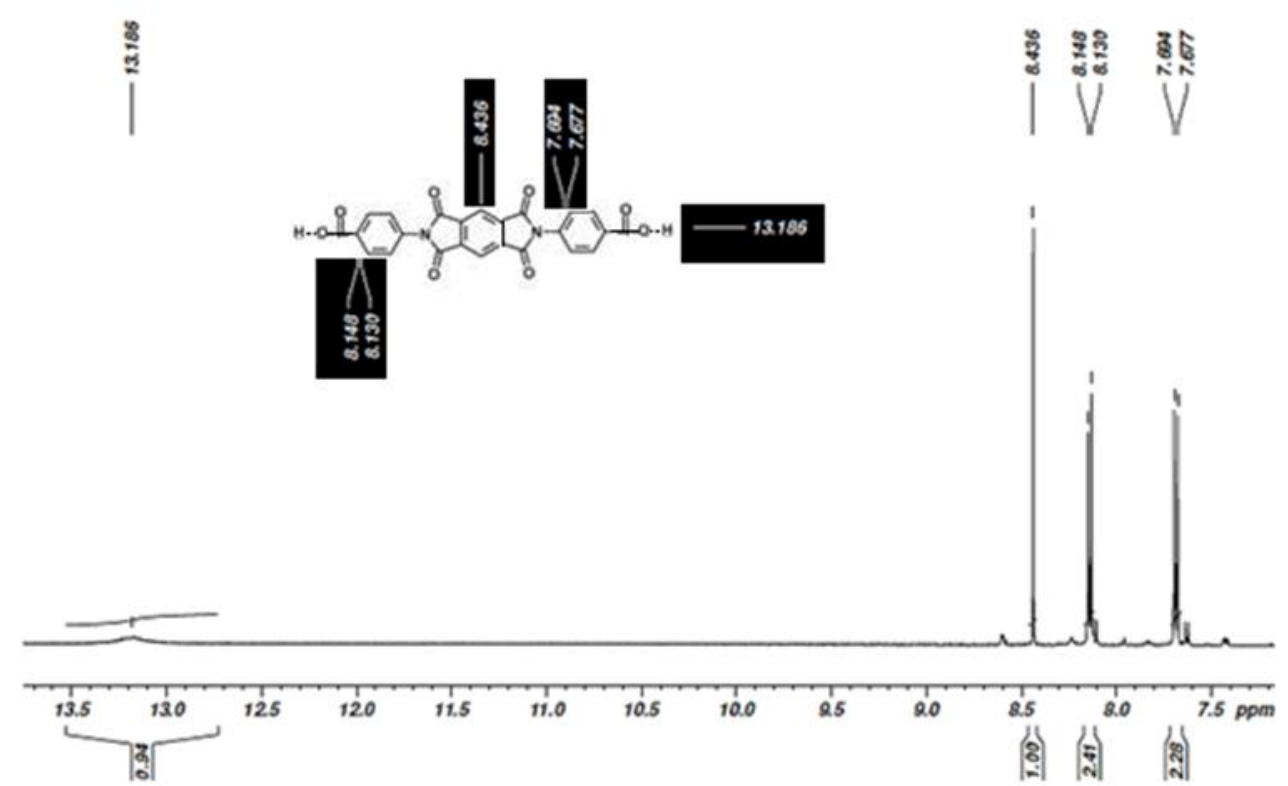

Figure 2: ${ }^{1} \mathrm{H}-\mathrm{FT}-\mathrm{NMR}$ spectra for N,N'-Bis(carboxyphenyl)pyromellitimide

The results (Table 1) show an excellent yield in which that the work-up procedures were very simple. As the reaction time was completed the reaction mixture cooled to room temperature then the solid product washed with cooled water and methanol. The synthesis reaction carried out simply and easy using modified domestic microwave without temperature control in which that the microwave radiation supplies enough energy to make the reaction mixture refluxed at the short time of reaction.

\section{Conclusion}

This work involved synthesis of several bispyromellitimides by the reaction of pyromellitic anhydride with aniline or its derivatives (a-h) using microwave irradiation. The result demonstrated that microwave heating is an efficient method for synthesis bispyromellitimides in compare to classical synthesis reaction and leads to pure higher yields, cleaner reactions and shorter reaction times.

\section{Acknowledgements}

The FT-NMR laboratory support provided through Ma'am Shubha Pyria and Mr. Marwan Al Saedi, Oxbridge College of Pharmacy, Bangalore, India is warmly acknowledged.

\section{References:}

1- GiguereR. J., Bray T. L., Duncan S. M., MajetichG. 1986.Application of commercial microwave ovens to organic synthesis. TetrahedronLett. 27. 4945-4948.

2- TsoleridisC. A.,Neochoritis C. G.,Tzitzikas T., Stephanidou-StephanatouJ., KontogiorgisC. A., Hadjipavlou-LitinaD. J., Choli-PapadopoulouT. 2011.One-pot microwave assisted synthesis under green chemistry conditions, antioxidant screening, and cytotoxicity assessments of benzimidazole Schiff bases and pyrimido[1,2-a]benzimidazol-3(4H)ones.European Journal of Medicinal Chemistry. 46. 297-306.

3- Prasad D., Preetam A., NathM. 2012.Microwave-assisted green synthesis of dibenzo[a,j]xanthenes using pdodecylbenzenesulfonic acid as an efficient Bronsted acid catalyst under solvent-free conditions. ComptesRendusChimie.15, 675-678.

4- Wang S., , Cheng C., , Wu F., , Jiang B., , Shi F., , TuS., RejaleT. Li G. 2011.Microwave-assisted multi-component reaction in water leading to highly regioselective formation of benzo[f]azulen-1-ones. Tetrahedron 67. 4485-4493.

5- GedyeR. N., Rank W.,WestawayK. C. 1991.The rapid synthesis of organic compounds in microwave ovens. II. Canadian Journal of Chemistry 69.706-711. 
6- ScharnD., Wenschuh H., ReinekeU., Schneider-MergenerJ.,GermerothL. 2000.; Spatially Addressed Synthesis of Amino- and Amino-Oxy-Substituted 1,3,5-Triazine Arrays on Polymeric Membranes J. CombChem. 2 . 361-369.

7- DahmaniZ., RahmouniM., BrugidouR., BazureauJP.,Hamelin J. 1998.A new route to $\alpha$-hetero $\beta$-enamino esters using a mild and convenient solvent-free process assisted by focused microwave irradiation. TetrahedronLett. 39. 8453-8456.

8- GedyeRN., Smith E., Westaway K., Ali Baldisera H.,LabergeL.,Rousell J. 1986. The use of microwave ovens for rapid organic synthesis. Tetrahedron let. 27. 279.

9- KatritzkyAR., Zhang Y., Singh SK., Steel PJ. 2003.1,3-Dipolar cycloadditions of organic azides to ester or benzotriazolylcarbonyl activated acetylenicamides. Arkivoc, xv, 47-64.

10- Imai Y., NemotoH., Watanabe S., KakimotoM. A. 1996.A New Facile and Rapid Synthesis of Aliphatic Polyamides by Microwave Assisted Polycondensation of $\omega$-Amino Acids and Nylon Salts.Polym. J.28. 256.

11- MallakpourS., ShahmohammadiM. H. 2005.Synthesis of NewOptically Active Poly(amide-imide)s Derived from $N, N$ (pyromellitoyl)-bis-S-valine Diacid Chloride and Aromatic Diamines under Microwavelrradiation and Classical Heating.Iranian Polymer Journal 14. 473-483.

12- Faghihih., HajibeygiM. 2004. Synthesis and properties of new poly(amide imide)s containing trimellitic rings and hydantoin moieties in the main chain under microwave irradiationJ. of Appl. Polym. Sci., 92, 3447-3453.

13- Faghihi K. 2004.Microwave assisted rapid synthesis of novel optically active poly(amide-imide)s based on $N$ trimellitylimido-L-leucine diacid chloride and hydantoinderivatives.Macromol Research 12.258-262.

14- Kricheldorf H. R., Schwarz G., DomschkeA., Linzer V. 1993.Liquid Crystalline Polyimides 15. Role of Conformation and Donor.Acceptor Interactions for the Nematic Order of Poly(ester-imide)s Macromolecules 26. 5161.

15- KricheldorfH. R., Pakull R. 1987. New polymer syntheses: 21. LC-poly(ester imide)s prepared from trimellitic acid, $\alpha, \theta-$ diaminoalkanes and various hydroquinones or dihydroxynaphthalenes Polymer 28.1772-1778.

16- Hsiao S. H., Yang C. P. J. 1990.Preparation of polyamide-imides via the phosphorylation reaction. II. Synthesis of wholly aromatic polyamide-imides from $N$-[ $p$-(or $m$-) carboxyphenyl]trimellitimides and various aromatic diaminesPolym. Sci. Part A: Polym. Chem. 28.1149.

17- De Abajo J., de la CampaJ. G. 1999. Processable Aromatic Polyimides.Adv Pol Sci. 140. 23-59.

18- Mallakpour S.KolahdoozanM. 2006. Preparation and Characterization of Novel Optically Active Poly(Amide-EsterImide)sBased on Bis(p-aminobezoic acid)-Ntrimellitylimido-S-valine via Direct Polyesterification. Iran Polymer Journal 15 (4). 307-315.

19- N. E. Searle U. S. Pat.2 444 536, 1948, Chem. Abstr. 42, 7340 (1948)

20- FaghihiK.. 2007. Facile and Rapid Synthesis of Some Optically Activelmide-Acid Derivatives Using Microwave Irradiation J. Sci. I .A . U (JSIAU) 17 2-177.

21- Ondruš V., FišeraL.r,BradacV. 2001. On the use of water as a solvent - simple and short one- stepsynthesis of maleimides ARKIVOC V.60-67.

22- Faghihi K., ShabanianM., GhadiryL. 2010. NewCopolyamidesContainingGAzobenzene Groups and Different Diacid and Diamine In The Main Chain: Synthesis And Characterization. J. Chil. Chem. Soc. 55. 212.

23- FaghihiK.,Fouroghifar N.,Zamani K., HajibeygiM., MallakpourS. 2003. Iranian Polymer Journal, 12, 339-346.

24- FaghihiK., AsghariA., HajibeygiM. 2013.Synthesis And Characterization OF Thermally StablePoly(Amide-Imide)Montmorillonite Nanocomposites Based On Bis(4-Carboxyphenyl)-N,N'-Pyromellitimide Acid. Bull. Chem. Soc. Ethiop. 27, 95-104. 